\title{
Efficacy of artemether-lumefantrine in treatment of malaria among under-fives and prevalence of drug resistance markers in Igombe-Mwanza, north-western Tanzania
}

Erasmus Kamugisha ${ }^{1 *}$, Sun Jing ${ }^{2}$, Mercy Minde ${ }^{1}$, Johaness Kataraihya ${ }^{1}$, Gilbert Kongola ${ }^{1}$, Fred Kironde ${ }^{3}$ and Göte Swedberg ${ }^{2}$

\begin{abstract}
Background: Drug resistance to anti-malarials is a major public health problem worldwide. This study aimed at establishing the efficacy of artemether-lumefantrine (ACT) in Igombe-Mwanza, north-western Tanzania after a few years of ACT use, and establish the prevalence of mutations in key targets for artemisinin, chloroquine and sulphadoxine/pyrimetamine (SP) drugs.
\end{abstract}

Methods: A prospective single cohort study was conducted at lgombe health centre using artemetherlumefantrine combination therapy between February 2010 and March 2011. The follow-up period was 28 days and outcome measures were according to WHO guidelines. Blood was collected on Whatman filter paper for DNA analysis. DNA extraction was done using TRIS-EDTA method, and mutations in Pfcrt, Pfmdr1, Pfdhfr, Pfdhps and Pfatp6 were detected using PCR-RFLP methods established previously.

Results: A total of 103 patients completed the 28 days follow-up. The mean haemoglobin was $8.9 \mathrm{~g} / \mathrm{dl}$ (range 5.0 to $14.5 \mathrm{~g} / \mathrm{dl}$ ) and mean parasite density was 5,608 parasites/ $\mu$ l. Average parasite clearance time was 34.7 hours and all patients cleared the parasites by day 3 . There was no early treatment failure in this study. Late clinical failure was seen in three (2.9\%) patients and late parasitological failure (LPF) was seen in two (1.9\%). PCR-corrected LPF was $1 \%$ and adequate clinical and parasitological response was $96 \%$. The majority of parasites have wild type alleles on pfcrt 76 and pfmdr1 86 positions being $87.8 \%$ and $93.7 \%$ respectively. Mutant parasites predominated at pfdhfr gene at the main three positions 108, 51 and 59 with prevalence of $94.8 \%, 75.3 \%$ and $82.5 \%$ respectively. Post-treatment parasites had more wild types of pfdhps at position 437 and 540 than pre-treatment parasites. No mutation was seen in pfatp6 769 in re-infecting or recrudescing parasites.

Conclusion: The efficacy of artemether-lumefantrine for treatment of uncomplicated malaria is still high in the study area although the rate of re-infection is higher than previously reported. Parasite clearance after 48 hours was lower compared to previous studies. The prevalence of wild type allele pfcrt $76 \mathrm{~K}$ and pfmdr $186 \mathrm{~N}$ was high in the study area while markers for SP resistance is still high. Artemether-lumefantrine may be selecting for wild type alleles on both positions (437 and 540) of pfdhps.

Keywords: pfcrt, pfmdr1, pfdhfr, pfdhps, pfatp6, Mutations

\footnotetext{
* Correspondence: erasmuskamugisha@yahoo.com

'Weill-Bugando University College of Health Sciences, Mwanza, Tanzania

Full list of author information is available at the end of the article
} 


\section{Background}

Drug resistance to anti-malarials is a major public health problem worldwide [1]. In 2006, Tanzania changed policy from use of sulphadoxine-pyrimethamine (SP) as a firstline drug for treatment of uncomplicated malaria to artemether-lumefantrine combination therapy (AL) [2]. This was a second change following the first change from chloroquine (CQ) to SP in 2001 [3,4]. This milestone is similar in many African countries where malaria is endemic. A change of anti-malarial drug policy has been derived by development of drug resistance to commonly used drugs by the Plasmodium parasites, especially Plasmodium falciparum which causes more than $90 \%$ of infection in sub-Saharan Africa. Although there are reports of decreasing paediatric malaria infection $[5,6]$ and burden of malaria [1]; malaria is still a major public health disease causing 243 million cases every year, of which over $85 \%$ are in Africa. Malaria led to 863,000 deaths in 2008 and $89 \%$ of them occurred in the sub-Saharan Africa region [1]. Data from the field are now reporting emergence of what is referred to as artemisinin resistance due to increased number of parasites, which shows delayed clearance from blood circulation on artemisinin combination therapy (ACT) [7]. Clinical trials carried out so far in Africa shows high efficacy of AL combination therapy [8-11]. Hunt et al, 2009 reports that analysis of studies in East Africa shows that the parasites were being controlled less well by the artemisinin component of ACT in 2007/ 2008 studies than in 2005/2006 [12]. As these reports are coming up, the mechanism of action of artemisinin is not known yet, a few target genes have been suggested with inconclusive findings [13-16]. Treatment with AL has led to selection of wild type alleles at molecular markers for CQ resistance (pfcrt $76 \mathrm{~K}$ and pfmdr1 $86 \mathrm{~N}$ ) with a concomitant reduction in susceptibility to lumefantrine [17]. Even before introduction of AL, re-emergence of wild types for $p f c r t$ has been reported in Malawi with restored sensitivity to CQ $[18,19]$. It is not known whether it is the use of lumefantrine, absence of CQ in the field or both factors acting in synergy that leads to selection of CQ susceptible parasites. Tanzania is a country that has significantly minimized the use of CQ for about 10 years now but continues to use SP for IPTp (intermittent presumptive treatment in pregnancy). In such a situation there is a need to continue monitoring the efficacy of AL in endemic areas and prevalence of molecular markers for drug resistance so as to give evidence-based data to national malaria control programmes. This study aimed at establishing the efficacy of AL in Igombe, Mwanza, north-western Tanzania, after a few years of AL use and establish the prevalence of mutations in key targets for artemisinin, chloroquine and sulphadoxine/pyrimetamine (SP) drugs.

\section{Methods}

\section{Study area and design}

This was an interventional prospective single cohort study conducted at Igombe health centre in the vicinity of Mwanza city in Tanzania. In this area malaria is mesoendemic and the catchment area for Igombe health centre is a semi-urban, with a population of around 40,000 inhabitants.

\section{Recruitment of patients}

Patients with fever, aged between six and 60 months who attended the clinic during the study periods (between February 2010 and July 2010 and between October 2010 and March 2011) were screened for malaria parasites. Detailed medical history, clinical examination and both thick and thin blood films were done after obtaining an informed consent from the parents or guardian. Recruitment was based on inclusion criteria set by WHO [20] (parasitaemia between 2,000 and 200,000 asexual stage parasites/ $\mu$ l, axillary temperature $\geq 37.5^{\circ} \mathrm{C}$ ). Patients must not have history of antimalarial use in the last 14 days, no signs of severe malaria or danger signs and no other infections.

\section{Treatment of patients and follow-up}

A six-dose regimen of artemether-lumefantrine (Co$\operatorname{artem}^{\circledR}$, Novartis, Basel, Switzerland) was used to treat recruited patients. A first dose was given as a direct observed therapy (DOT) and the next doses was supplied to the parents/caretakers for giving to patients at eight hours from the time of the first dose and morning and evenings of successive two days. For patients weighing from $5 \mathrm{~kg}$ to less than $14 \mathrm{~kg}$ a single tablet $(20 \mathrm{mg} /$ $120 \mathrm{mg}$ artemether/lumefantrine) was given, those from $15 \mathrm{~kg}$ to less than $24 \mathrm{~kg}$ received two tablets, those with 25 to less than $34 \mathrm{~kg}$ received three tablets. Patients with fever and axillary body temperature $\geq 38.5^{\circ} \mathrm{C}$ were given paracetamol and those with anaemia ( $\mathrm{Hb}$ between 5 and $9 \mathrm{~g} / \mathrm{dl}$ ) were given haematinics. If a patient vomited the treatment drug within 30 minutes the dose was repeated and those who vomited more than once were excluded from the study and changed to parenteral quinine. Patients were followed up on days 1, 2, 3, 7, 14, 21 and 28. Patients were reminded of their visiting dates by mobile phones if the parents owned one, or through the 10 cell-leaders' phones; those who did not turn up on the scheduled days were visited by a member of the research team. A patient was withdrawn from the study if the follow-up was not complete and could not be traced the following day and these included patients who travelled to other places. Also use of other antimalarial drugs or non-compliance especially to the 
second dose at eight hours led to withdrawal of patients from the study.

According to WHO in vivo test protocol [20] the outcomes were classified into early treatment failure (ETF), late clinical failure (LCF), late parasitological failure (LPF) and adequate clinical and parasitological response (ACPR).

ETF was defined as the occurrence of one of the following signs: signs of severe disease or danger signs on day 1, 2 or 3 with parasitaemia, level of parasitaemia on day 2 that exceeded that on day 0 , an axillary temperature of $37.5^{\circ} \mathrm{C}$ or higher on day 3 in the presence of parasitaemia or a level of parasitaemia on day 3 that was at least $25 \%$ of the level at time of enrolment.

LCF was defined as the occurrence (to patients who did not have ETF) of one of the following during days 4 to 28: danger signs, severe malaria or an axillary temperature of $37.5^{\circ} \mathrm{C}$ or higher in the presence of parasitaemia.

LPF was defined as presence of parasitaemia on any day from day 7 to day 28 without signs of severe disease or fever and not previously meeting criteria of ETF or LCF

ACPR was defined as absence of parasitaemia on day 28 irrespective of axillary temperature without previously meeting any of the criteria of ETF, LTF or LPF

\section{Ethical clearance}

The study was approved by the Joint Weill-Bugando ethical clearance committee and informed consent was obtained from the parents/guardians of all patients.

\section{Blood sample collection and haemoglobin estimation} On day of recruitment finger prick was done aseptically and blood was spotted on Whatman no 1 filter paper, thick and thin blood smears were done and stained with Giemsa. A venopunture was done and $3 \mathrm{ml}$ of blood was taken in EDTA vacutainer for full blood count (including haemoglobin estimation) using Cell Dyn 3700 machine (Abbot Laboratories USA). On follow-up only, finger prick blood was collected and spotted on filter papers.

\section{Molecular analysis}

DNA was extracted from dried blood spot on filter paper using TRIS-EDTA method [21] and stored at $-20^{\circ}$ $\mathrm{C}$ until future use. Mutations on pfcrt position 76 were determined using primers and RFLP performed as explained elsewhere [22]. Pfmdr1 gene was also amplified by nested PCR and RFLP done according to protocols published before [23]. For $p f d h f r$, outer PCR was done using primer $p f d h f r 1$ and $p f d h f r 2$ and nested PCR was done using primer $p f d h f r 3$ and $p f d h f r 4$ for position 108 and pfdhfr 5 and pfdhfr 6 for nested reaction on position 51 and 59 (see Tables 1 and 2 for PCR primers and programmes). The pfdhps gene covering positions 540 and 437 was amplified and digested using primers and protocols published previously [24]. For pfatp6 positions 263 and 769, PCR-RFLP methods described by Kamugisha et al, 2011 and Sisowath et al, 2007 were used $[25,26]$. All PCR products and restriction digests were separated by agarose gel electrophoresis and visualized using UV trans-illuminator. Distinction between re-infection and recrudescence was done using PCR and RFLP on $m s p-2$ gene as previously described [27]. Data were analysed using SPSS version 17.

\section{Results}

A total of 1,040 children under five years of age, with fever, were screened for malaria parasites during the study period. Five hundred and seventy six (55.4\%) were found positive for malaria parasites but only 108 met the inclusion criteria and were recruited (Figure 1). Five patients could not complete the study, three of these were lost to follow-up while one was referred due to severe vomiting (vomited the drug twice) and another patient was not compliant as he did not take the dose at eight hours. Therefore 103 patients completed the 28 days follow-up and were analysed.

Males were 52 (51.5\%) and females were 51 (49.5\%) and the average age was 38.7 months. The mean haemoglobin was $8.9 \mathrm{~g} / \mathrm{dl}$ (range 5.0 to $14.5 \mathrm{~g} / \mathrm{dl}$ ), and mean parasite density was 5,608 parasites $/ \mu$ l (ranging from $2,000$ to 56,800 parasites $/ \mu \mathrm{l})$.

Average parasite clearance time was 34.7 hours, 70 (68\%) cleared parasites within the first 24 hours and cumulatively $91(88.4 \%)$ patients had cleared the parasites at 48 hours. The remaining $12(11.7 \%)$ patients had positive blood slide at day 2 and they were all cleared of parasites by day 3 (Figure 2). Only one patient had fever on day 2 and others had fever resolution within the first 24 hours.

Table 1 Primers used for pfdhfr amplification

\begin{tabular}{ll}
\hline Name & Sequence \\
\hline $\begin{array}{l}\text { Pfdhfr1 (outer } \\
\text { forward) }\end{array}$ & 5'-ATG ATG GAA CAA GTC TGC GAC-3' \\
\hline $\begin{array}{l}\text { Pfdhfr2(outer } \\
\text { reverse) }\end{array}$ & 5'-C TTG ATA AAC AAC GGA ACC TCC-3' \\
\hline $\begin{array}{l}\text { Pfdhfr3(nested } \\
\text { forward) }\end{array}$ & 5'-ACT ACA CAT TTA GAG GTC TAG G-3' \\
\hline $\begin{array}{l}\text { Pfdhfr4(nested } \\
\text { reverse) }\end{array}$ & 5'-GG TTC TAG ACA ATA TAA CAT TTA TCC-3' \\
\hline $\begin{array}{l}\text { Pfdhfr5(nested } \\
\text { forward) }\end{array}$ & 5'-GCC ATA TGT GCA TGT TGT AAG GTT GAA AG- \\
\hline $\begin{array}{l}\text { Pfdhfr6(nested } \\
\text { reverse) }\end{array}$ & 5'-CAT ATT TTG ATT CAT TCA CAT ATG TTG TAA \\
\hline
\end{tabular}


Table 2 Programme used for pfdhfr amplification

\begin{tabular}{|c|c|}
\hline Name & PCR programme \\
\hline Outer & $\begin{array}{l}94^{\circ} \mathrm{C} 3 \mathrm{~min} ; 5 \mathrm{cycles}: 94^{\circ} \mathrm{C} 30 \mathrm{sec}, 56^{\circ} \mathrm{C} 30 \mathrm{sec}, 72^{\circ} \mathrm{C} 45 \mathrm{sec} ; 8 \text { cycles: } 92^{\circ} \mathrm{C} 30 \mathrm{sec}, 55^{\circ} \mathrm{C} 30 \mathrm{sec}, 72^{\circ} \mathrm{C} 45 \mathrm{sec} ; 12 \mathrm{cycles}: 92^{\circ} \mathrm{C} 30 \mathrm{sec} \text {, } \\
53^{\circ} \mathrm{C} 30 \mathrm{sec}, 72^{\circ} \mathrm{C} 45 \mathrm{sec} ; 18 \mathrm{cycles}: 92^{\circ} \mathrm{C} 30 \mathrm{sec}, 50^{\circ} \mathrm{C} 30 \mathrm{sec}, 72^{\circ} \mathrm{C} 45 \mathrm{sec} ; 16^{\circ} \mathrm{C} \text { hold }\end{array}$ \\
\hline $\begin{array}{l}\text { Nested } \\
\text { (pfdhfr3 } \\
\text { +pfdhfr4) }\end{array}$ & $94^{\circ} \mathrm{C} 3 \mathrm{~min} ; 30$ cycles: $94^{\circ} \mathrm{C} 1 \mathrm{~min}, 50^{\circ} \mathrm{C} 1 \mathrm{~min}, 72^{\circ} \mathrm{C} 1 \mathrm{~min} ; 72^{\circ} \mathrm{C} 10 \mathrm{~min} ; 4^{\circ} \mathrm{C}$ hold \\
\hline $\begin{array}{l}\text { Nested } \\
\text { (pfdhfr5 } \\
\text { +pfdhfr6) }\end{array}$ & $94^{\circ} \mathrm{C} 3 \mathrm{~min} ; 30$ cycles: $94^{\circ} \mathrm{C} 1 \mathrm{~min}, 55^{\circ} \mathrm{C} 1 \mathrm{~min}, 72^{\circ} \mathrm{C} 1 \mathrm{~min} ; 72^{\circ} \mathrm{C} 10 \mathrm{~min} ; 4^{\circ} \mathrm{C}$ hold \\
\hline
\end{tabular}

There was no ETF in this study, LCF was seen in three $(2.9 \%)$ patients, LPF was seen in two $(1.9 \%)$ and ACPR was achieved in 98 (95.1\%) patients before correction with PCR. PCR corrected LPF was $1 \%$ and ACPR was 96\% (Table 3).

A high number of subpatent infections were detected by PCR (while looking at the drug resistance markers) but not microscopy on both day 14 and day 28 raising the prevalence to $15(14.6 \%)$ and $13(12.6 \%)$ respectively. All subpatent infections were due to re-infections as shown by different $m s p 2$ patterns.

\section{Molecular markers for drug resistance Pfcrt 76 position}

A total of 90 samples were successfully amplified at position 76 of pfcrt gene (success rate $87.4 \%$ ) and among these, the majority 80 (88.9\%) were wild type and only $10(11.1 \%)$ were mutants. On follow-up samples, after treatment with AL, 12 samples were successfully amplified on day 14 and 28 , of which a majority, eight (66.7\%), were wild type alleles and four (33.3\%) were mutant alleles. The difference between pre-treatment samples and re-infections could not be shown to be significant (Table 4).

\section{Pfmdr1 86 position}

At this position the wild type were higher, 89 (93.7\%) (including 85 pure wild types and four mixed, with wild types dominating) and pure mutants were only six (6.3\%). Among the 19 successfully amplified post-treatment samples, the wild type alleles were still in majority at $11(57.9 \%)$ but the proportion of mutants had increased to $42.1 \%$, which is a significant change (Table 4). All mutants in post-treatment samples did not come from same patients with mutation at day 0 .

\section{Pfdhfr position 108, 51 and 59}

For $p f d h f r$, successful amplification was achieved in 97 samples (success rate 97.2\%). At position 108, 92 (94.8\%) were mutant while four (4.3\%) were wild type and one $(1.1 \%)$ was a mixed infection.

At position 51, the majority $73(75.3 \%)$ were mutant while $12(12.4 \%)$ were wild type and the other 12 (12.4\%) were mixed with more mutants.
At position $59,80(82.5 \%)$ were mutant and nine $(9.3 \%)$ were wild type, while eight $(8.2 \%)$ were mixed with more mutants. The prevalence of triple mutants in pfdhfr gene in pre-treatment samples was high with 59 samples (64.1\%) while 27 (29.4\%) had double mutation with various combinations as illustrated in Table 5 .

In post-treatment samples, mutants were predominant but at a lower percentage than at day 0: $21 / 29(74.2 \%)$, $20 / 29(69 \%)$ and $15 / 29(51.7 \%)$ on position 108, 51 and 59 respectively. In the post-treatment samples the triple mutants were 13/29 (44.8\%) and double mutants were $7 / 29$ (24.1\%) (Table 5). About eleven patients (47.8\%) were mutants in both pre-and post-treatment samples.

\section{Pfdhps gene position 540 and 437}

A total of 95 samples were successfully amplified at position 540 and 66 (69.5\%) were mutants, while 15 (15.8\%) were wild type and 14 (14.7\%) were mixed with more mutants. At pfdhps 437, 96 samples were successfully amplified and $71(74.0 \%)$ were mutants while 15 (15.6\%) were wild type and $10(10.4 \%)$ were mixed (with mutants predominating). Double mutants in pfdhps were 65 (68.4\%) out of 95 samples, which amplified at both positions. With the exception of one sample, all mutants at position 540 were also mutants at position 437. There were more wild types at both positions in pfdhps in the follow-up samples at day 14 and 28 after treatment with ACT. Prevalence of wild types were 10/ $17(58.8 \%)$ and $13 / 21(61.9 \%)$ at positions 437 and 540 respectively.

\section{Pfatp6 position 263 and 769}

There was no mutation in pfatp 6 at position 263 in either pre-treatment or post-treatment samples. At position 769 , mutations were screened only in re-infection and recrudescing parasites and no mutation was detected in these follow-up samples.

\section{Discussion}

The efficacy of AL in this study area was high at $95.1 \%$ (PCR uncorrected) and 96\% PCR corrected. This is similar to what has been found in other places of Tanzania and Sub-Saharan Africa in general where cure rates ranged from 96 to 100 in children [8-11,28]. The 


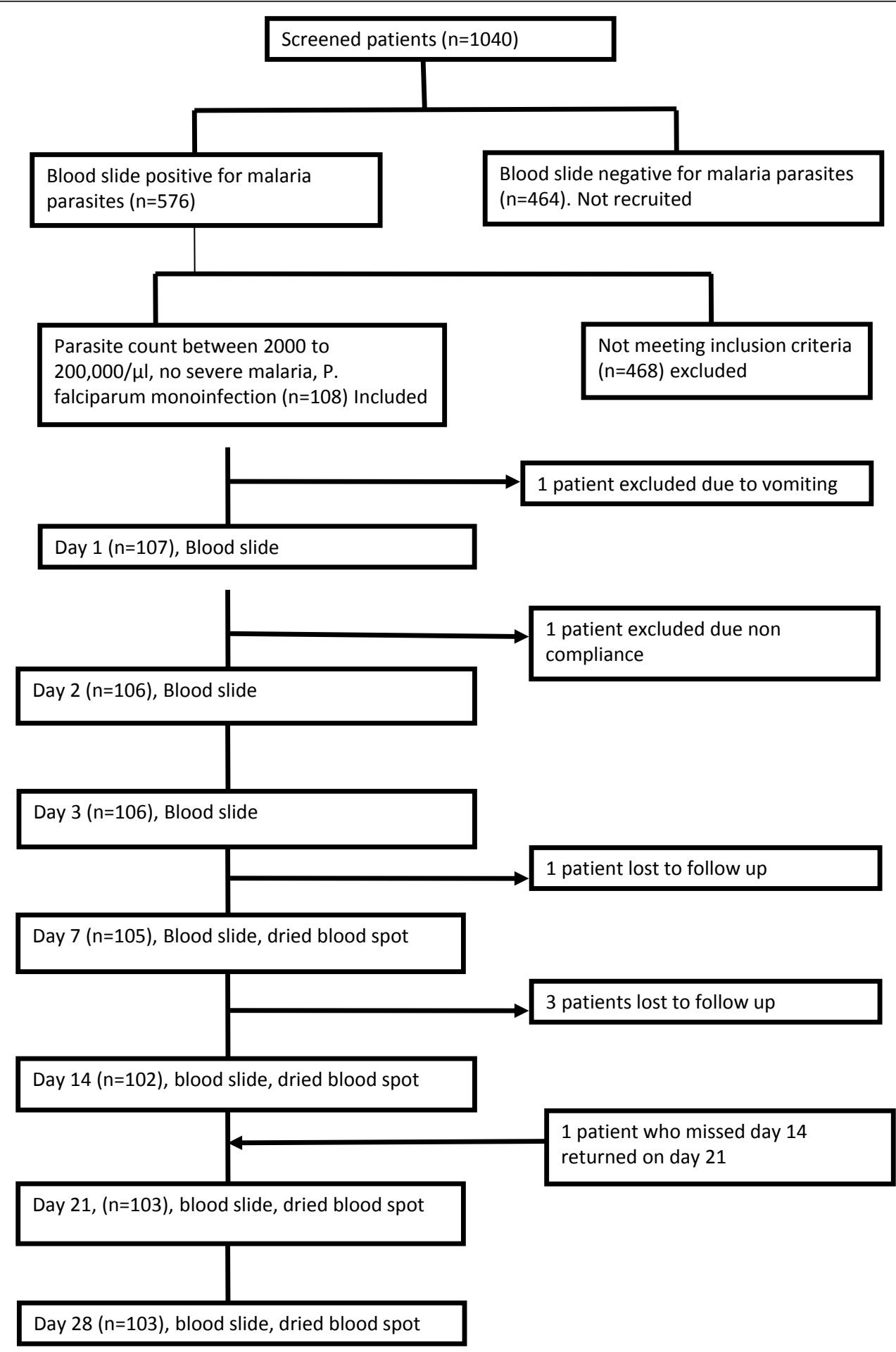

Figure 1 Patient recruitment and follow-up for 28 days in Igombe.

percentage of re-infection in this study was higher compared to the findings in the above studies. However, a more recent study, Ngasala et al, showed similar high frequencies of LPF as shown here [29]. The meeting proceedings reported by Hunt et al [12], presented evidence of parasites in East Africa being less well controlled in 2007/2008 studies compared to studies in $2005 / 2006$. This may be the beginning of what is 


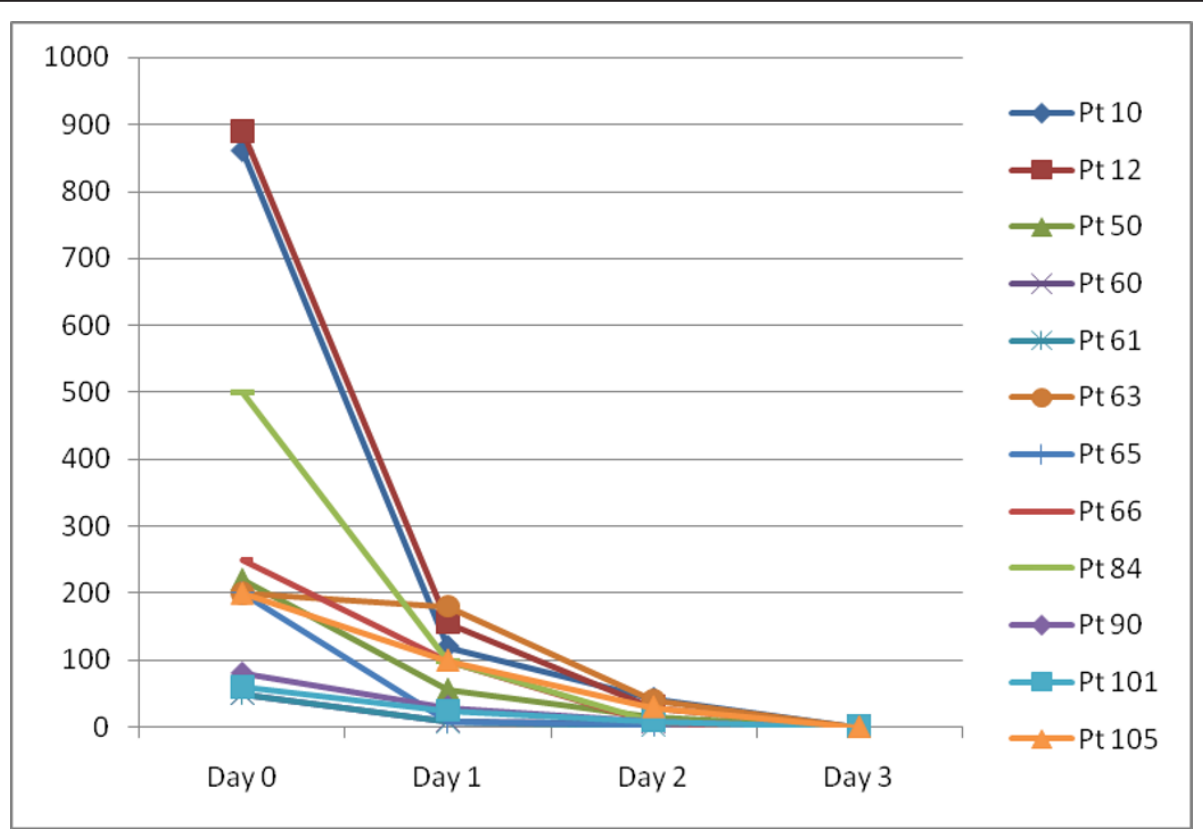

Figure 2 Parasite clearance in 12 patients who had parasitaemia on day 2.

referred to as reduced efficacy of artemisinin combination therapies seen in South-east Asia [7]. In this study recrudescence was low $1 \%$. The mean parasite clearance time in this study was 34.7 hours, which is consistent with what was reported in 2005[8]. The percentage of patients that had cleared the parasites by 48 hours was lower compared to previous studies; this may be an indicator of emergence of the resistant, dormant parasites reported in South-east Asia. The fact that no parasites were extended beyond day 3 shows that this ACT is still more efficacious in Africa than has been seen in South-east Asia. This may be explained by proper use of $\mathrm{ACT}$ and relatively short time of use compared to South-east Asia. The main combination in South-east Asia is artemisinin-mefloquine, which may explain some of the difference.

The prevalence of parasites with wild type alleles ( $p f c r t$ $76 \mathrm{~K}$ and $p f m d r 186 \mathrm{~N}$ ) is high in this study area compared to other studies done previously in Tanzania. This is a good indicator of return of CQ-sensitive parasites as was shown in Malawi study where Laufer et al, found good in vivo sensitivity to CQ following a study that revealed decline in mutants (pfcrt76T) at this position [19]. The findings in this study could be due to both proper control of CQ [30] or the selection of wild type by use of AL therapy [17]. This adds to the evidence that reduction in the drug pressure in malaria parasites leads to re-emergence of wild type, which has been documented [18]. The decline seen in Tanzania seems to be similar to what was seen in Malawi but differs from what is seen in Kenya and Uganda, the immediately neighbouring countries in the northern part of Tanzania; this is attributed to continued use of certain amounts of CQ in these countries [30]. In Gabon, the prevalence of pfcrt mutations was reported to be high more than five years after discontinued use of CQ [31].

Table 3 PCR corrected and uncorrected cure rate

\begin{tabular}{lllll}
\hline & No & \% Prevalence PCR uncorrected & No & \% Prevalence PCR corrected \\
\hline ETF & 0 & 0.0 & 0 & 0.0 \\
\hline LCF & 3 & 2.9 & 0 & 0.0 \\
\hline LPF & 2 & 1.9 & 1 & 1.0 \\
\hline ACPR & 98 & 95.1 & 95 & 96 \\
\hline Total analysis & 103 & & 99 & \\
\hline Withdrawal & 2 & & 4 & \\
\hline Loss to follow-up & 3 & & & \\
\hline Total & 108 & &
\end{tabular}


Table 4 Prevalence of mutations in pfcrt, pfmdr1, pfdhfr and pfdhps in pre-treatment and post-treatment samples

\begin{tabular}{llll}
\hline Position (N) & Mutants (n) & Percentage & P-value \\
\hline Pfcrt 76 & & 11.1 & \\
\hline Pre-treatment (90) & 10 & 33.3 & 0.22 \\
\hline Post-treatment (12) & 4 & & \\
\hline Pfmdr1 86 & & 6.3 & 0.0000 \\
\hline Pre-treatment (95) & 6 & 42.1 & \\
\hline Post-treatment (19) & 8 & & \\
\hline Pfdhfr108 & & 94.8 & \\
\hline Pre-treatment (97) & 92 & 74.2 & \\
\hline Post-treatment (29) & 21 & & \\
\hline Pfdhfr 51 & & 75.3 & \\
\hline Pre-treatment (97) & 73 & 69.0 & \\
\hline Post-treatment (29) & 20 & & \\
\hline Pfdhfr 59 & & 82.5 & 0.0009 \\
\hline Pre-treatment (97) & 80 & 51.7 & 0.0003 \\
\hline Post-treatment (29) & 15 & 38.1 & \\
\hline Pfdhps 437 (N) & & 33.3 & \\
\hline Pre-treatment (96) & 71 & 7 & \\
\hline Post-treatment (21) & 7 & & \\
\hline Pfdhps 540 & & & \\
\hline Pre-treatment (95) & 66 & & \\
\hline Post-treatment (21) & 8 & & \\
\hline
\end{tabular}

In this case, the high prevalence could be explained by the inclusion of amodiaquine in artemisinin-based treatment. There was however, a surprisingly high frequency of mutations in pfcrt and pfmdr1 in subpatent re-infections found in follow-up samples. This contrasts with most earlier studies, but a similar tendency for $p f c r t$ is

Table 5 Prevalence of Pfdhfr mutations at position 108, 51,59

\begin{tabular}{lll}
\hline $\mathbf{N}=\mathbf{9 2}$ Pre-treatment & $\mathbf{n}$ & $\%$ \\
\hline Triple mutants & 59 & 64.1 \\
\hline Double mutants $108 / 51$ & 10 & 10.9 \\
\hline Double mutants $108 / 59$ & 2 & 2.2 \\
\hline Double mutants $59 / 51$ & 1 & 1.1 \\
\hline Double mutants 108 with $59 / 51$ and mix at third position & 15 & 16.3 \\
\hline Single mutants & 5 & 5.4 \\
\hline $\mathbf{N}=\mathbf{2 3}$ Post-treatment & & \\
\hline Triple mutants & 13 & 56.5 \\
\hline Double mutants $108 / 51$ & 2 & 8.7 \\
\hline Double mutants $108 / 59$ & 2 & 8.7 \\
\hline Double mutants $59 / 51$ & 0 & 0 \\
\hline Double mutants 108 with $59 / 51$ and mix at third position & 3 & 13.0 \\
\hline Single mutants & 3 & 13.0 \\
\hline
\end{tabular}

observed in Ngasala et al, where at least no significant difference in $p f c r t$ frequencies were found in re-infections [29]. The remaining pfcrt and pfmdr1 mutations indicates that it will be very difficult to completely reverse CQ resistance once the resistance has been established and reusing CQ may lead to rapid emergence of CQ resistance. Any attempt to reuse CQ should only be done under proper controls where the in vitro susceptibility can be monitored.

On the other hand the prevalence of triple and double pfdhfr mutants in Mwanza is very high $64.1 \%$ and 29.4\% compared to that reported previously in this area [3]. This could be explained by the continued use of SP in IPTp and probably in the treatment of malaria as the change of policy from SP to ACT did not go hand in hand with the ban of SP as occurred with CQ. The prevalence of triple and double mutants in this place creates the doubt on the usefulness of continued use of these drugs in IPTp but also removes hope of the possibility of combining these drugs with artemisinins. However, in re-infections lower level of mutants were seen for $p f d h f r$ and more dramatically for pfdhps indicating a possible rapid return to SP susceptibility with continued use of AL.

\section{Conclusions}

The efficacy of artemether-lumefantrine for treatment of uncomplicated malaria was still high in the study area although the rate of re-infection was high. There was a high number of patients who got subpatent malaria infection after treatment with ACT, which was diagnosed by PCR later at day 14 or 28 . The prevalence of $p f c r t 76 \mathrm{~K}$ and $p f m d r 186 \mathrm{~N}$ was high in the study area while markers for SP resistance shows that the resistance to SP may still be very high and even increasing. Artemether-lumefantrine may be selecting for wild type alleles on both positions (437 and 540) of pfdhps

\section{Acknowledgements \\ We acknowledge the assistance from clinical staff and laboratory staff of Igombe health centre for assisting in the clinical trial, also the parents and guardians of the patients who agreed to participate in this study and adhered to the follow-up schedule. We thank Innocent Rweyemamu for following up patients in the villages and Bernard Okamo for the laboratory work in Weill-Bugando laboratory.}

\section{Author details}

${ }^{1}$ Weill-Bugando University College of Health Sciences, Mwanza, Tanzania. ${ }^{2}$ Uppsala University, Uppsala, Sweden. ${ }^{3}$ Makerere University, Kampala, Uganda.

\section{Authors' contributions}

EK, SJ and GS carried out the molecular genetic studies and drafted the manuscript. MM, JK and EK carried out field study, patients follow-up and drafted the manuscript. GK, FK and GS conceived the study, and participated in its design and coordination. All authors read and approved the final manuscript. 


\section{Competing interests}

The authors declare that they have no competing interests.

Received: 8 December 2011 Accepted: 27 February 2012 Published: 27 February 2012

\section{References}

1. WHO: WHO Malaria report Geneva: World Health Organization; 2009 .

2. National Malaria Control Programme, Ministry of Health: Malaria treatment guidelines Dar es Salaam, Tanzania: Ministry of Health; 2006.

3. Mugittu K, Ndejembi M, Malisa A, Lemnge M, Premji Z, Mwita A, Nkya W, Kataraihya J, Abdulla S, Beck HP, Mshinda H: Therapeutic efficacy of sulfadoxine-pyrimethamine and prevalence of resistance markers in Tanzania prior to revision of malaria treatment policy: Plasmodium falciparum dihydrofolate reductase and dihydrofolate synthase mutations in monitoring in vivo resistance. Am J Trop Med Hyg 2004, 71:696-702.

4. National Malaria Control Programme, Ministry of Health: Malaria treatment guidelines Dar es Salaam, Tanzania: Ministry of Health; 2000.

5. Ceesay SJ, Casals-Pascual C, Erskine J, Anya SE, Duah NO, Fulford AJ, Sesay SS, Abubakar I, Dunyo S, Sey O, Palmer A, Fofana M, Corrah T, Bojang KA, Whittle HC, Greenwood BM, Conway DJ: Changes in malaria indices between between 1999 and 2007 in the Gambia: a retrospective analysis. Lancet 2008, 372:1545-1554.

6. O'Meara WP, Bejon P, Mwangi TW, Okiro EA, Peshu N, Snow RW, Newton CR, Marsh K: Effect of a fall in malaria transmission on morbidity and mortarity in Kilifi, Kenya. Lancet 2008, 372:1555-1562.

7. Dondorp AM, Nosten F, Yi P, Das D, Phyo AP, Tarning J, Lwin KM, Ariey F, Hanpithakpong W, Lee SJ, Ringwald P, Silamut K, Imwong M, Chotivanich K, Lim P, Herdman T, An SS, Yeung S, Singhasivanon P, Day NPJ, Lindegardh N, Socheat D, White NJ: Artemisinin resistance in Plasmodium falciparum malaria. N Engl J Med 2009, 361:455-467.

8. Falade C, Makanga M, Premji Z, Ortmann CE, Stockmeyer M, De Pelacios PI: Efficacy and safety of artemether-lumefantrine (Co-artem) tablets (sixdose regimen) in African infants and children with acute, uncomplicated falciparum malaria. Trans R Soc Trop Med Hyg 2005, 99:459-467.

9. Makanga M, Premii Z, Falade C, Karbwang J, Mueller EA, Andriano K Hunt P, De Pelacios PI: Efficacy and safety of six-dose regimen of artemether-lumefantrine in pediatrics with uncomplicated Plasmodium falciparum malaria: a pooled analysis of individual patient data. Am J Trop Med Hyg 2006, 74:991-998.

10. Achan J, Tibenderana JK, Kyabayinze D, Wabwire Mangen F, Kamya MR, Dorsey G, DÁlessandro U, Rosenthal PJ, Talisuna AO: Effectiveness of quinine versus artemether-lumefantrine for treating uncomplicated falciparum malaria in Ugandan children: randomised trial. BMJ 2009, 339 : b2763.

11. Tshefu AK, Gaye O, Kayentao K, Thompson R, Bhatt KM, Sesay SS, Bustos DG, Tjitra E, Bedu-Addo G, Borghini-Fuhrer I, Duparc S, Shin CS, Fleckenstein L, Pyronaridine-artesunate Study Team: Efficacy and safety of a fixed-dose oral combination of pyronaridine-artesunate compared with artemether-lumefantrine in children and adults with uncomplicated Plasmodium falciparum malaria: a randomised non inferiority trial. Lancet 2010, 375:1457-1467.

12. Hunt $P$, Macinnis B, Roper C: Malaria genomics meets drug-resistance phenotyping in the field. Genome Biol 2009, 10:314.

13. Uhlemann AC, Cameron A, Eckstein-Ludwig U, Fischbarg J, Iserovich P, Zuniga FA, East M, Lee A, Brady L, Haynes RK, Krishna S: A single amino acid residue can determine the sensitivity of SERCAs to artemisinins. Nat Struct Mol Biol 2005, 12:628-629.

14. Jambou R, Legrand E, Niang M, Khim N, Lim P, Volney B, Ekala MT, Bouchier C, Esterre P, Fandeur T, Mercereau-Puijalon O: Resistance of Plasmodium falciparum field isolates to in-vitro artemether and point mutations of the SERCA-type Pfatpase6. Lancet 2005, 366:2012-2018.

15. Hunt $P$, Afonso A, Creasey A, Culleton $R$, Sidhu AB, Logan J, Valderramos SG, McNae I, Cheesman S, do Rosario V, Carter R, Fidock DA, Cravo P: Gene encoding a deubiquitinating enzyme is mutated in artesunate and chloroquine-resistant rodent malaria parasites. $\mathrm{Mol}$ Microbiol 2007, 65:27-40.

16. Wang J, Huang L, Li J, Fan O, Long Y, Li Y, Zhou B: Artemisinin directly targets malarial mitochondria through its specific mitochondrial activation. PLoS One 2010, 5:e9582.
17. Sisowath C, Strömberg J, Mårtensson A, Msellem M, Obondo C, Björkman A, Gil JP: In vivo selection of Plasmodium falciparum pfmdr1 $86 \mathrm{~N}$ coding alleles by artemether-lumefantrine (Coartem). J Infect Dis 2005, 191:1014-1017.

18. Kublin JG, Cortese JF, Njunju EM, Mukadam RA, Wirima JJ, Kazembe PN, Djimde AA, Kouriba B, Taylor TE, Plowe CV: Reemergence of chloroquinesensitive Plasmodium falciparum malaria after cessation of chloroquine use in Malawi. J infect Dis 2003, 187:1870-1875.

19. Laufer MK, Thesing PC, Eddington ND, Masonga R, Dzinjalamala FK, Takala SL, Taylor TE, Plowe CV: Return of chloroquine antimalarial efficacy in Malawi. N Engl J Med 2006, 355(19):1959-1966.

20. WHO: Assesment and monitoring of antimalarial drug efficacy for the treatment of uncomplicated malaria, WHO/HTM/RBM/2003.50.

21. Bereczky S, Mårtenson A, Gil JP, Färnert A: Rapid DNA extraction from archive blood spots on filter paper for genotyping of Plasmodium falciparum. Am J Trop Med Hyg 2005, 72:249-251.

22. Djimde A, Doumbo OK, Cortese JF, Kayentao K, Doumbo S, Diourte $Y$, Dicko A, Su XZ, Nomura T, Fidock DA, Wellems TE, Plowe CV: A molecular marker for chloroquine-resistant falciparum malaria. N Engl J Med 2001, 344:257-263.

23. Duraisingh MT, Jones P, Sambou I, Seidlein L, Pinder M, Warhurst DC: The Tyrosine-86 allele of the pfmdr1 gene of Plasmodium falciparum is associated with increased sensitivity to the antimalarials mefloquine and artemisinin. Mol Biochem Parasitol 2000, 108:13-23.

24. Duraisingh MT, Curtis J, Warhurst D: Plasmodium falciparum: Detection of polymorphisms in the dihydrofolate reductase and dihydropteroate synthetase genes by PCR and restriction digestion. Exp Parasitol 1998, 89:1-8.

25. Kamugisha E, Sendagire $H$, KadduMukasa M, Enweji N, Gheysari F, Swedberg G, Kironde F: Detecting adenosine triphosphatase 6 (PfATP6) point mutations that may be associated with Plasmodium falciparum resistance to artemisinin: prevalence at baseline, before policy change in Uganda. Tanzan J Health Res 2011, 13:50-60.

26. Sisowath C, Ferreira P, Bustamante LY, Dahlström S, Mårtensson A Björkman A, Krishna S, Gil JP: The role of Pfmdr1 in Plasmodium falciparum tolerance to artemether-lumefantrine in Africa. Trop Med Int Health 2007, 12:736-742.

27. Beck HP, Felger I, Huber W, Steiger S, Smith T, Weiss N, Alonso PL, Tanner M: Analysis of multiple Plasmodium falciparum infections in Tanzanian children during the phase III trial of malaria vaccine SPf66. Infect Dis 1997, 175:921-926.

28. Assefa A, Kassa M, Tadese G, Mohamed H, Animut A, Mengesha T: Therapeutic efficacy of artemether/lumefantrine (Coartem) against Plasmodium falciparum in Kersa, South West Ethiopia. Parasit Vectors 2010, 3:1.

29. Ngasala BE, Malmberg M, Carlsson AM, Ferreira PE, Petzold MG, Blessborn D, Bergqvist Y, Gil JP, Premji Z, Björkman A, Mårtensson A: Efficacy and effectiveness of artemether-lumefantrine after initial and repeated treatment in children $<5$ years of age with acute uncomplicated Plasmodium falciparum malaria in rural Tanzania: a randomized trial. Clin Infect Dis 2011, 52:873-882.

30. Frosch AEP, Venkatesan M, Laufer MK: Patterns of chloroquine use and resistance in sub-Saharan Africa: a systematic review of household survey and molecular data. Malaria J 2011, 10:116.

31. Frank M, Lehners N, Mayengue PI, Gabor J, Dal-Bianco M, Kombila DU, Ngoma GM, Supan C, Lell B, Ntoumi F, Grobusch MP, Dietz K, Kremsner PG: A thirteen-year analysis of Plasmodium falciparum populations reveals high conservation of the mutant pfcrt haplotype despite the withdrawal of chloroquine from national treatment guidelines in Gabon. Malar $J$ 2011, 10:304.

doi:10.1186/PREACCEPT-6142726864727876

Cite this article as: Kamugisha et al.: Efficacy of artemether-lumefantrine in treatment of malaria among under-fives and prevalence of drug resistance markers in Igombe-Mwanza, north-western Tanzania. Malaria Journal 2012 11:58. 